\title{
Erratum to: The joint IAEA, EANM, and SNMMI practical guidance on peptide receptor radionuclide therapy (PRRNT) in neuroendocrine tumours
}

\author{
L. Bodei • J. Mueller-Brand • R. P. Baum • M. E. Pavel • \\ D. Hörsch • M. S. O'Dorisio • T. M. O'Dorisio • \\ J. R. Howe • M. Cremonesi • D. J. Kwekkeboom • \\ J. J. Zaknun
}

Published online: 28 December 2013

(C) Springer-Verlag Berlin Heidelberg 2013

\section{Erratum to: Eur J Nucl Med Mol Imaging \\ DOI 10.1007/s00259-012-2330-6}

The authors were listed in the wrong order, and one of their names was spelt incorrectly. These mistakes are rectified here.

The online version of the original article can be found htt://dx.doi.org/ $10.1007 / \mathrm{s} 00259-012-2330-6$

L. Bodei

Division of Nuclear Medicine, European Institute of Oncology,

Milan, Italy

J. Mueller-Brand

Klinik und Institut für Nuklearmedizin, Universitätsspital Basel,

Basel, Switzerland

\section{R. P. Baum • D. Hörsch}

Zentralklinik Bad Berka, Department of Internal Medicine, Gastroenterology and Endocrinology, ENETS Center of

Excellence, Bad Berka, Germany

\section{E. Pavel}

Campus Virchow Klinikum, Klinik für Gastroenterologie, Hepatologie, Endokrinologie, Diabetes und Stoffwechselerkrankungen, Charité Universitaetsmedizin Berlin, Berlin, Germany

\section{S. O’Dorisio}

RJ and LA Carver College of Medicine, Department of Pediatrics, University of Iowa, Iowa City, IA, USA

\section{T. M. O’Dorisio}

RJ and LA Carver College of Medicine, Department of Internal Medicine, University of Iowa, Iowa City, IA, USA
J. R. Howe

RJ and LA Carver College of Medicine, Department of Surgical Oncology, University of Iowa, Iowa City, IA, USA

M. Cremonesi

Service of Health Physics, European Institute of Oncology, Milan, Italy

\section{J. Kwekkeboom}

Department of Nuclear Medicine, Erasmus Medical Center Rotterdam, Rotterdam, The Netherlands

J. J. Zaknun $(\bowtie)$

Nuclear Medicine Section, Division of Human Health, International Atomic Energy Agency, IAEA, Vienna, Austria e-mail: J.zaknun@hotmail.com

\section{J. J. Zaknun}

e-mail: John.Zaknun@Zentralklinik.de

\section{J. J. Zaknun}

Zentralklinik Bad Berka, Center for Molecular Radiotherapy and Molecular Imaging, ENETS Center of Excellence, Bad Berka, Germany 